\title{
Effect of Ethnicity in Exostosis Prevalence
}

\section{Celia Elena Mendiburu-Zavala ${ }^{1, *}$, Marisol Ucan-Pech², Ricardo Peñaloza-Cuevas ${ }^{1}$, Pedro Lugo-Ancona ${ }^{1}$, Rubén Armando Cárdenas-Erosa ${ }^{1}$ and David Cortés-Carrillo ${ }^{1}$}

${ }^{1}$ Faculty of Dentistry, Autonomous University of Yucatan, Merida, Yucatan, Mexico

${ }^{2}$ Student of the Master's Degree in Pediatric Dentistry of the Autonomous University of Mexico, Mexico

*Corresponding author: Celia Elena Mendiburu-Zavala, Full-time Professor, Faculty of Dentistry, Autonomous University of Yucatan, Merida, Yucatan, Mexico, Tel: 9992923184; E-mail: cel_mendi@hotmail.com; mzavala@correo.uady.mx

Received: 06 Jun, 2019 | Accepted: 11 Jun, 2019 | Published: 17 Jun, 2019

Citation: Mendiburu-Zavala CE, Ucan-Pech M, Peñaloza-Cuevas R, Lugo-Ancona P, Cárdenas-Erosa R, et al. (2019) Effect of Ethnicity in Exostosis Prevalence. Int J Dent Oral Health 5(5): dx.doi.org/10.16966/2378-7090.299

Copyright: (C) 2019 Mendiburu-Zavala CE, et al. This is an open-access article distributed under the terms of the Creative Commons Attribution License, which permits unrestricted use, distribution, and reproduction in any medium, provided the original author and source are credited.

\section{Abstract}

Objective: To determine the effect of ethnicity in exostosis prevalence, from August 2016 to February 2017.

Materials and Methods: Comparative, observational and descriptive approach. Sample size was 900 inhabitants who provided informed consent. Inclusion criteria: born and living in Ticopo, Yucatan, Mexico; age of 10 years or older; male or female; presence or absence of exostosis on maxilla and/or mandible.

Variables: Surname-based ethnicity; age; sex; presence/absence of torus and/or exostosis; exostosis shape/location/position; and environmental factors. Three ethnicities were identified based on Maya surnames: Maya indicated by two Maya surnames (e.g. YaEk); Mestizo by one Maya and one non-Maya surname (e.g. YaLópez); and Non-Maya by no Maya surnames (e.g. López Figueroa). Data collected on demographic, environmental, ethnic and clinical factors. Logistical regression used to analyze data.

Results: Maya subjects were the majority (62\%) of the sample, and this ethnicity was related to presence of exostosis $\left(\chi^{2}=9.8189, \mathrm{P}=0.0436, \mathrm{~g} . \mathrm{l}=2\right)$. Twenty subjects excluded due to simultaneous presence of palate and mandibular exostosis. Females ( $n=57$ ) most frequently exhibited it among the Maya, while males $(n=30)$ exhibited more among the Mestizos. Of the 59 palate exostosis the most common form (55\%) was planar in all three ethnicities. Of the 100 mandibular exostosis, whorl was the most common shape among the Non-Maya, and lobular among the Maya and Mestizos.

Conclusions: Torus/exostosis prevalence was higher among the Maya than in the Mestizo and Non-Maya. The results support greater frequency of torus/exostosis among mongoloid ethnicities such as the Maya in comparison to other ethnicities.

Keywords: Exostosis; Ethnicity; Maya; Mestizo; Mongoloid

\section{Introduction}

The presence of multiple small bony nodules protruding from the alveolar bone is known as exostosis or torus (meaning "to stand out" in the Latin), depending on the anatomical location. Histologically they exhibit the same characteristics. They grow slowly and progressively, are convex in shape, have a smooth surface, are benign, abnormal, circumscribed and of normal color. Composed largely of dense cortical bone, they also contain scarce spongy bone covered with a thin, poorly irrigated layer of mucus. In the mouth, they are termed exostosis when located on the vestibular surface of the mandible and maxilla, generally near the premolars and molars; Torus Palatinus (TP) when on the palate of the maxilla; and Torus Mandibularis (TM) when on the inner surface of the mandible, opposite the mental foramen [1-3]. Toripalatinus occur along the median line of the palate as a circumscribed increase in volume which is hard, and the underlying mucus membrane is very fine. They are normal in color but can occasionally be hypo colored, they cause no pain, grow slowly and tend to appear in the first years of life [4,5]. Torimandibularis develop on the interior surface of the mandible, most frequently near the premolars. They have various shapes and sizes, are most often (more than $80 \%$ ) bilateral but can be unilateral, lobulated, multiple and grow in the mylohyoid line [4].

Also known as "bone hamartomas" [6], exostosis and tori are of unknown etiology. Most probably multifactor, they can be attributed to factors such as genetics, the environment, nutrition and occlusal trauma. A genetic, or ethnic, source is suggested by their high frequency in those of East Asian ancestry and low frequency in those of European ancestry. Moreover, when one or both parents have any type of torus, their children have a 40 to $64 \%$ probability of developing one, and when a relative has a torus incidence in children is 5 to $8 \%$. These anomalies may be due to the same autosomic gene, since exostosis incidence varies by ethnicity; for example, ranges are from 6 to 12.5\% among Europeans and Africans [7-12]. However, environmental factors have also been proposed as the first to initiate 
this process, and that genetic factors are later expressed in the patient; in other words, both genetic and environmental factors influence exostosis etiology $[9,11]$.

Over 10 million people belong to indigenous ethnic groups in Mexico, and the group with the greatest qualitative and quantitative weight is the Maya. The Maya of the Yucatan Peninsula are the second largest indigenous group in Mexico [13]. In the state of Yucatan (population 985,549) the Maya population represents $50.39 \%$ of the total population, which is also $59.2 \%$ of the Maya population on the Peninsula [14]. In other words, they outnumber other ethnicities in the region, as well as the Yucatan's non-indigenous population $[13,14]$. Over half the state's population has a surname of Maya origin, suggesting they belong to an ethnicity of common history and origin, and therefore also share a cultural fabric that has provided them cultural and ethnic continuity $[15,16]$. Of the approximately 250 Maya surnames, $70 \%$ are monosyllabic and derive from words for flora (Aban-bush, Nic-flower, Aké-liana, Ya-Achraszapota, TamayZuelaniasouzae, Canché-Conocarpus erectus, Copó-Ficusctinifolia, etc.), fauna (Can-snake, Pech-tick, Mass-cricket, Couoh-tarantula, Cabbee, Kanxoc-shark, Pat-baby shark, etc.), and nature (Ek'-star,Chaakrain, Tun-year, Uh-moon, Be-road or path, tun-stone, Uitz-hill, etc.), among others. Many Maya surnames remain unchanged from when they were first recorded by the Spanish in the $16^{\text {th }}$ Century, and others have changed only minimally [17].

Some of those in the state of Yucatan with one or two Spanish surnames may have parents (one or both) from other parts of Mexico (largely the states of Tabasco, Veracruz and Chiapas). A small number are the descendants of the Yaqui indigenous population forced to migrate to the region in the early $20^{\text {th }}$ Century [15].

Exostosis is reported to be more prevalent among people of the mongoloid racial phenotype. "Race" as a concept arose in the $19^{\text {th }}$ Century as part of an effort to identify human taxonomies and categories based on phenotypical features and genealogies [18]. The Centralid mongoloid phenotype is found largely from the southwest United States to northern South America, and is generally characterized by a brachycephalic cranium, low height, robust physique, and dark to light brown skin color. Since the Maya of Yucatan fall within this phenotype the present study objective was to analyze the effect of ethnicity in exostosis prevalence in a population of a small town in Yucatan, Mexico.

\section{Materials and Methods}

A comparative, observational and descriptive approach was applied to the population of the rural town of Ticopo, Yucatan, Mexico, from August 2016 to February 2017. The universe was the 1,660 inhabitants of the town, and the sample consisted of the 900 (54.2\%) inhabitants (490 male, 410 female) who, after an explanation of the study, gave their informed consent to participate in it. Inclusion criteria included being born and living in Ticopo; age of 10 years or older; male or female, presence or absence of maxillary and/or mandibular exostoses. Based on a 2016 federal map of the town, inhabitants were recruited by canvassing block by block from south to north.

Primary among the study variables was surname, which was used to classify participants into one of three ethnicity groups according to the relative presence or absence of Maya surnames: Maya; Mestizo; and Non-Maya. Maya ethnicity was determined based on the presence of two Maya surnames (e.g. YaEk), and in which the subject's parents, and paternal and maternal grandparents, all had two Maya surnames. Mestizo ethnicity was identified by the presence of one Maya surname and one Non-Maya surname (e.g. YaLópez). Non-Maya ethnicity was indicated when a subject had no Maya surname (e.g. López Figueroa). The sample was also grouped by age (adolescent: 10-19 years; young adult: 20-39 years; mature adult: 40-59 years; elder adult: $60+$ years); sex (male, female); exostosis location (maxillary or mandibular); exostosis shape (lobular, whorl, nodular or planar); and environmental factors (type of diet, type of water consumed).

A form was designed for data collection that included demographic information (surnames, age, sex), exostosis/torus characteristics (shape, location and position), diagnosis as an exostosis or a solid, hard and circumscribed torus, and environmental and ethnicity factors. Participants were asked to fill out a questionnaire on eating habits and the type of water they consumed.

Clinical examinations were done of each participant's mouth following applicable guidelines (e.g. use of disposable gloves, cap, mask and tongue depressor; NOM-013-SSA2-2006). Subjects were seated and a visual inspection made using a flashlight, and a tongue depressor to separate the cheeks and tongue from the oral surfaces. Mouth structures were examined by palpating with the index finger and thumb in this order: 1 . upper right quadrant; 2 . upper left quadrant; 3. lower left quadrant; and 4. lower right quadrant. If an exostosis and/ or torus was detected its shape, location and position were recorded.

\section{Statistical Analysis}

A logistical regression $\left(\chi^{2}\right)$ analysis was run to identify any relationship between the presence of exostosis and the predictive variables (age, sex and ethnicity).

\section{Results}

Of the 900 participants, most (62\%) were Maya, followed by Mestizos (30\%) and Non-Mayas (8\%). The largest age group (41\%) was mature adults ( 40 to 59 years) (Figure 1).

A total of 179 exostoses (maxillary, mandibular or both) were found among the participants, representing $19.9 \%$ of the sample. Of these, $67 \%$ (119/179) were found in Maya participants (Figure 2).

The chi-squared analysis identified a significant relationship

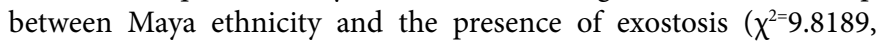
$\mathrm{P}=0.0436$, g.l $\mathrm{l}=2$ ). Twenty subjects exhibiting simultaneous palate and mandibular exostoses were excluded from this analysis to prevent double counts. As a result, the analysis was run with a sample 159 subjects with exostosis (18.1\% of total sample): Maya $(n=109 ; 69 \%)$; Mestizo ( $n=42 ; 26 \%)$; Non-Maya $(n=8 ; 5 \%)$ (Table 1$)$.

Exostosis frequency by age was highest among mature adults (6.9\%) in the Maya group, among young adults (2.6\%) in the Mestizo group and among elder adults (1.1\%) in the Non-Maya group. By sex, exostosis was most frequent in females $(n=57)$ in the Maya group, but most frequent among males $(n=30)$ in the Mestizo group (Table 2).

A total of 59 palate exostoses were identified among the three ethnic groups, the most frequent (55\%) shape being planar (Figure 3).

One hundred exostosis were identified in the mandible. The most frequent shape in the Non-Maya group was whorl, while lobular was the most frequent among the Maya and Mestizo groups, and whorl the least frequent (Figure 4 and 5).

Among the environmental factors, $98 \%$ of the surveyed population stated that their diet was mainly cooked animal meat with minor fruit and vegetable intake. Though varied, this diet is largely soft since most of the foods are cooked. Of the adolescent and young adult population, $5 \%$ stated that at some time they had consumed water from a shallow well; these are usually from 8 to 15 meters deep and common in rural 


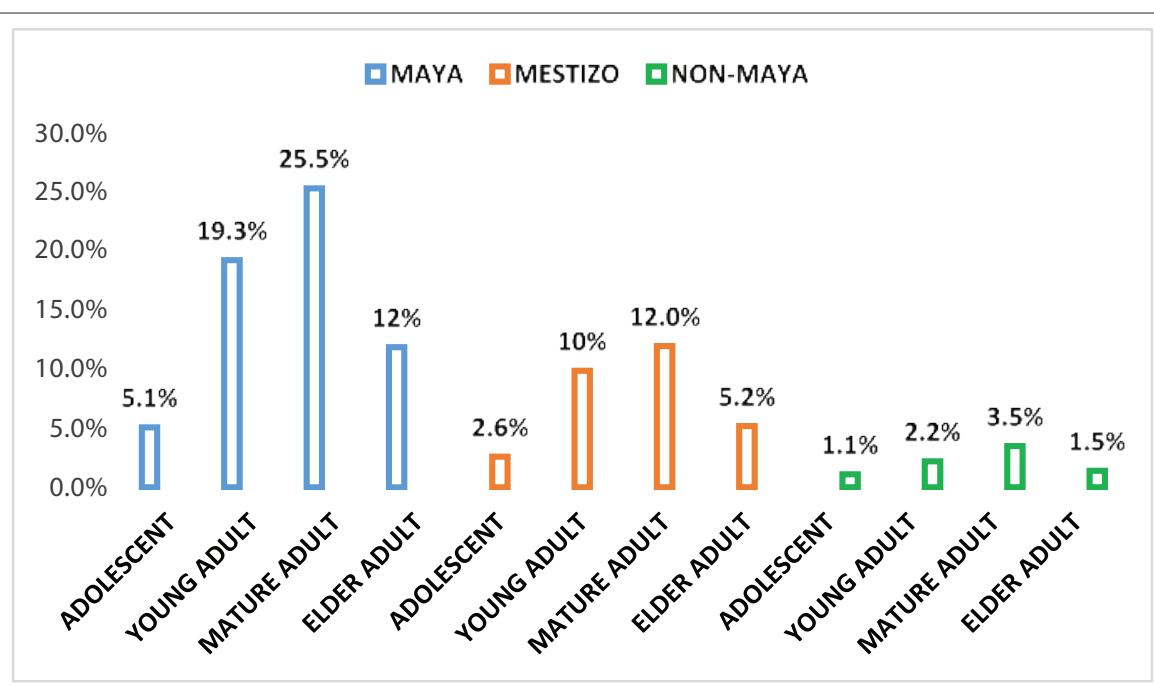

Figure 1: Age and ethnicity distribution of sample (n=900) from Ticopó, Yucatan, Mexico. 2016-2017.

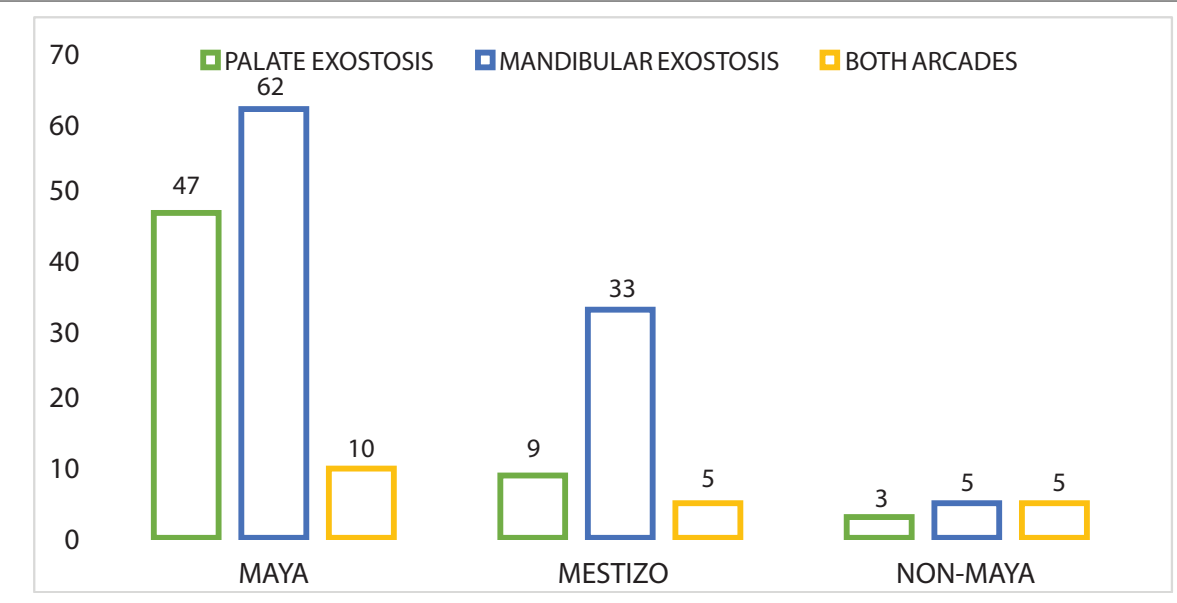

Figure 2: Distribution of palate, mandibular and both types among sample ( $n=179)$ by ethnicity in Ticopó, Yucatan, Mexico. 2016-2017.
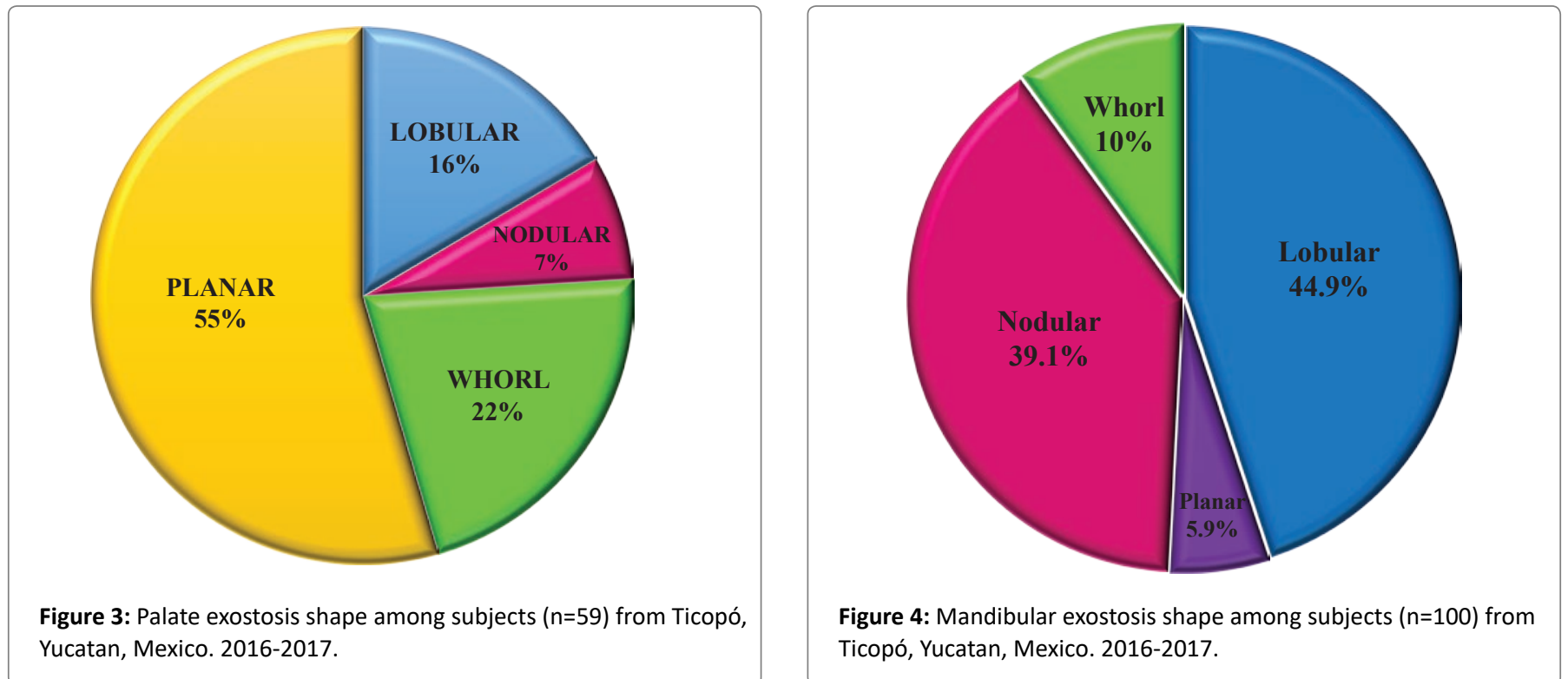

Citation: Mendiburu-Zavala CE, Ucan-Pech M, Peñaloza-Cuevas R, Lugo-Ancona P, Cárdenas-Erosa R, et al. (2019) Effect of Ethnicity in Exostosis Prevalence. Int J Dent Oral Health 5(5): dx.doi.org/10.16966/2378-7090.299 


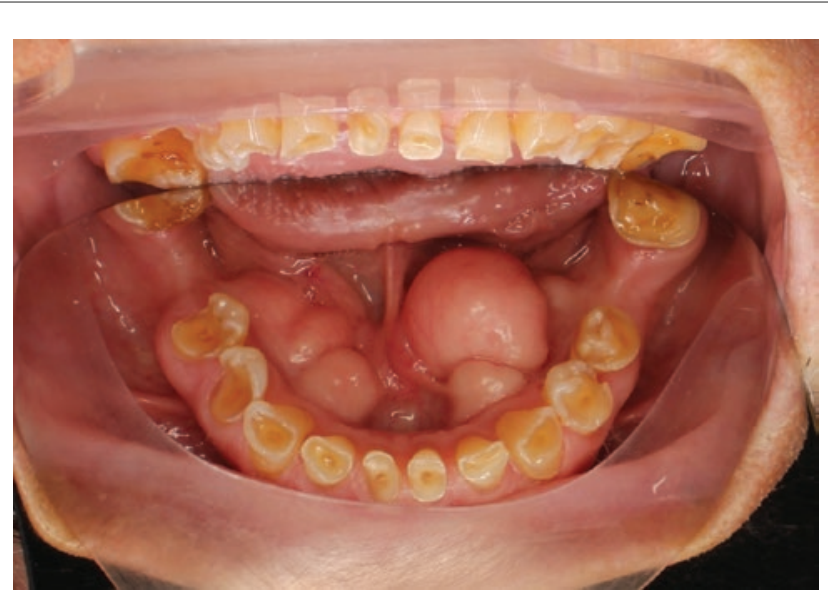

Figure 5: Male 72 years old. Mayan ethnic group. Mandible exostosis.

Table 1: Presence or absence of exostosis or torus by ethnicity group in sample $(n=880)$ from Ticopó, Yucatan, Mexico. 2016-2017.

\begin{tabular}{|l|c|c|c|c|c|}
\hline Ethnicity & Absent & $\begin{array}{c}\text { Palate } \\
\text { Exostosis }\end{array}$ & $\begin{array}{c}\text { Mandibular } \\
\text { Exostosis }\end{array}$ & $\begin{array}{c}\text { Total } \\
\text { Sample }\end{array}$ \\
\hline \multirow{2}{*}{ Maya } & Frequency & 438 & 47 & 62 & 547 \\
\cline { 2 - 6 } & $\%$ & 49.8 & 5.3 & 7 & 62.2 \\
\hline \multirow{2}{*}{ Mestizo } & Frequency & 222 & 9 & 33 & 264 \\
\cline { 2 - 6 } & $\%$ & 25.2 & 1 & 3.8 & 30 \\
\hline \multirow{2}{*}{ Non-Maya } & Frequency & 61 & 3 & 5 & 69 \\
\cline { 2 - 6 } & $\%$ & 6.9 & 0.3 & 0.6 & 7.8 \\
\hline \multirow{2}{*}{ Total } & Frequency & 721 & 59 & 100 & 880 \\
\cline { 2 - 6 } & $\%$ & 81.9 & 6.7 & 11.4 & 100 \\
\hline
\end{tabular}

Table 2: Absence or presence of exostosis by sex and ethnicity group in sample $(n=880)$ from Ticopó, Yucatan, Mexico. 2016-2017.

\begin{tabular}{|c|c|c|c|c|c|}
\hline Ethnicity & Sex & Absent & $\begin{array}{c}\text { Palate } \\
\text { Exostosis }\end{array}$ & $\begin{array}{c}\text { Mandibular } \\
\text { Exostosis }\end{array}$ & $\begin{array}{c}\text { Total } \\
\text { Exostoses }\end{array}$ \\
\hline \multirow{2}{*}{ Maya } & Male & 234 & 29 & 23 & 52 \\
\cline { 2 - 6 } & Female & 204 & 18 & 39 & 57 \\
\hline \multirow{2}{*}{ Mestizo } & Male & 135 & 5 & 25 & 30 \\
\cline { 2 - 6 } & Female & 87 & 4 & 8 & 12 \\
\hline \multirow{2}{*}{ Non-Maya } & Male & 44 & 2 & 2 & 4 \\
\cline { 2 - 6 } & Female & 17 & 1 & 3 & 4 \\
\hline & & & & & 159 \\
\hline
\end{tabular}

communities. In contrast, $76 \%$ of the mature adults stated they had consumed well water, and $100 \%$ of the elder adults stated they had; $54.3 \%$ stated they continued drinking well water.

\section{Discussion}

Of the various theories advanced to explain the etiology of exostosis/ torus, genetics and the limit theory apparently provide the most apt explanation. According to this theory the responsible environmental factors must first attain a certain limit or level before genetic factors can be expressed in the individual; in other words, both genetic and environmental factors determine expressivity [19]. Other factors may also effect etiology, such as eating habits, nutritional disturbances and masticatory hyperfunction stress [19].

Overall exostosis prevalence in the present results was $18.1 \%$; among the Maya subjects it was approximately $19.9 \%$ and among the Non-Maya it was approximately $11.6 \%$. These are both higher than the $6.7 \%$ exostosis frequency reported in a study 1,223 patients treated at the Faculty of Dentistry of the Autonomous University of Yucatan (Universidad Autonoma de Yucatán - UADY). However, exostosis location in these patients was mostly $(77.78 \%)$ mandibular with fewer (22.22\%) palate exostoses, which generally coincided with the present results in which $63 \%$ of the identified exostoses were mandibular and $37 \%$ were in the palate [20].

The difference between indigenous and non-indigenous populations observed here is similar to that reported among Mapuche and nonMapuche patients in Chile [21]. General exostosis prevalence among a probabilistic sample of 159 patients was $5.66 \%$, but increased to $14.28 \%$ in Mapuche patients and decreased to $4.34 \%$ in Non-Mapuches. Similarities are not apparent between the present results and those of a study done of 1,200 inhabitants of Santiago de Cali, Colombia, in which overall torus prevalence was $22.16 \%$ [22]. However, subjects with white skin had a much higher prevalence (56.4\%) than mestizos (21.8\%) and those of African ancestry (21.8\%). This contrasts with the much lower overall and ethnicity-specific prevalence's observed here, and with the highest prevalence being in dark-skinned (i.e., Maya) subjects.

A study done of 1,532 patients of three different ethnicities (Malay, Malay-Chinese and Indian) in northern Malaysia reported an overall prevalence of $12.5 \%$ (12\% TP and $2.8 \% \mathrm{TM})$. The Malay-Chinese ethnicity exhibited $18.7 \%$ prevalence, notably higher than those of the other two ethnicities [19], and similar to the higher prevalence observed in the present study for Maya subjects. Also, prevalence among the Malay-Chinese was higher among females, also observed in the present results for Maya subjects. In this study, torus shape was only classified as planar $(52.2 \%)$ or lobular (47.8\%), with a higher prevalence of planar tori in the maxilla and of lobular tori in the mandible. This precludes any comparison with the four exostosis shape categories used in the present results.

In a cohort study also done in Malaysia, 33\% $(n=882)$ of the 2,666 subjects were found to have a torus or exostosis [23]. When divided by ethnicity, prevalence was $65 \%$ among Chinese patients, $23 \%$ among Malays, 7\% among Indians and 5.3\% among other ethnicities. In the entire sample, torus location was the palate in $65 \%$ of cases, the mandible in $10.5 \%$, palate and mandible in $14 \%$, maxillary exostosis in $4.4 \%$, exostosis and palate torus in $3.6 \%$, mandibular exostosis in $1.7 \%$ and a combination of exostosis and palate and mandibular tori in $0.8 \%$. Among the Chinese, location was the palate in $63 \%$ of cases and the mandible in $11 \%$. The higher prevalence for the mongoloid (i.e., Chinese) ethnicity in this study coincides with the higher prevalence for the Maya in the present results.

At least one study supports a dominant genetic influence on the prevalence of oral bony outgrowths. These were studied in Lithuanian twins, of which $59.9 \%$ had oral bony outgrowths [24]. As was the case among the Maya subjects in the present study, most (56.8\%) of the outgrowths were mandibular in this study. Heritability estimates showed genetics to have the strongest influence on outgrowth etiology.

\section{Conclusion}

The Maya subjects exhibited higher torus/exostosis prevalence than the Mestizo and Non-Maya ethnicities, a tendency also reported for 
other mongoloid ethnicities (e.g., Chinese). Among the sexes, Maya females and Mestizo males had higher exostosis frequencies in the present results. Sex has no reported influence in other ethnicities. Exostoses in the maxilla were largely planar in shape while those on the mandible were mostly lobular. Environmental factors may have had some influence since more than half the Maya subjects had drunk well water containing high calcium $(\mathrm{Ca}++)$ levels. Further research is needed to confirm the extent to which the environment and genetics influence torus/exostosis occurrence in the ethnicities of Yucatan.

\section{Conflict of Interest}

No conflict of interest.

\section{References}

1. Nair AS, Kurien NM, Kumar SLK, Sivakumar TT, Varun V, et al. (2017) Large Lingual Tori: A Clinical Case Report. Med Case Rep Image 1: 1-6.

2. Derar Al-Sebaie, Alwrikat M (2011) Prevalence of torus palatinus and torus mandibularis in Jordanian population. Pakistan Oral and Dental Journal 31: 214-216.

3. Medsinge SV, Kohad R, Budhiraja H, Singh A, Gurha S, et al. (2015) Buccal Exostosis: A Rare Entity. J Int Oral Health 7: 62-64.

4. Sánchez BT, Figueredo EJ, Moreno ARE, Gregori TJ, Avila JOT (2013) Torus Palatinus and Torus Mandibularis in Patients Attended at Pedro Diaz Coello Polyclinic. CCM 17: 315-319.

5. García-García AS, Martínez-González JM, Gómez-Font R, SotoRivadeneira A, Oviedo -Roldán L (2010) Current status of the torus palatinus and torus mandibularis. Med Oral Patol Oral Cir Bucal 15: e353-e360.

6. Chandna S, Sachdeva S, Kochar D, Kapil H (2015) Surgical management of the bilateral maxillary buccal exostosis. J Indian Soc Periodontol 19: 352-355.

7. Osorio-Castillo MR, Alvarado-Marquez HA, Díaz-Caballero A (2008) Mandibular torus surgery. Duazary 5: 111-114.

8. Vidal MAM, Jiménez MMC, Luna RLM (2013) Prevalence of torus palatinus and torus mandibularis in school children from Cartagena, Colombia. Revista ADM 70: 197-201.

9. Miranda-Gutiérrez CR, Sánchez-Cruz MC (2014) Torus palatinus and mandibular in patients who seek care in the Dental Clinic of the Regional Military Hospital in Acapulco, Guerrero. Rev Sanid Milit Mex 68: 272-275.

10. Eroglu S, Erdal Y (2008) Why did the frequency of palatine torus increase in the ancient Anatolian populations? Homo 59: 365-382.

11. Pechenkina EA, Benfer RA Jr (2002) The role of occlusal stress and gingival infection in the formation of exostoses on mandible and maxilla from Neolithic China. Homo 53: 112-130.
12. Manotas Arevalo I, Pertuz Cala VL, Escorda SL (2005) Torus Palatino, Torus Mandibular y Exóstosis Maxilares. Revista de la Facultad de Ciencias de Salud 2: 115-123.

13. Krotz E (2004) Recent information on the indigenous population of the Yucatan Peninsula: data, contexts and reflections. Bulletin of Information and Economic Analysis of the Faculty of Economy of the UADY 59: 11-16.

14. Herrera JI, El Mekaoui AM (2016) The experience of anthropological expertise in the Mayan population of the state of Yucatan, Mexico. Revista Antropologías del Sur 3: 147-161.

15. Flores-Hernández M, Pérez-Rivas ME (2012) Alliances and Legitimization Strategies of the Indigenous Nobility in Northern Yucatán along the Postclassic: A Comparative and Multidisciplinary Approach. Estud Cult Maya 40: 123-166.

16. Guzmán-Medina M (2013) Language and identity among the contemporary Maya of Yucatan. Annals of Anthropology 47: 57-71.

17. Miguel Güémez Pineda (2011) Diccionario del Español Yucateco: Colección Bicentenario. Lenguas de nuestra Tierra. Universidad Autónoma de Yucatán, México 462.

18. García R (2017) En la línea de lo humano: la raza como instrumento de dominación. Sociales Investiga 3: 112-120.

19. Sathya K, Kanneppady SK, Arishiya T (2012) Prevalence and clinical characteristics of oral tori among outpatients in Northern Malaysia. J Oral Biol Craniofac Res 2: 15-19.

20. Peñaloza-Cuevas R, Rodríguez-Fernández MS, Lama-González E, Rodríguez-Casanova BI, Lara-Farfán F (2013) Prevalencia de exostosis en pacientes que acudieron a la Facultad de Odontología de la Universidad Autónoma de Yucatán (FOUADY). Rev Odontol Latinoam 5: 7-12.

21. Fuentes-Fernández R, Borie-Echeverria E, Parra-Villagran $P$, Rebolledo-Sooto K (2009) Torus palatino y torus mandibular. Int J Odontostomat 3: 113-117.

22. Guzmán-Marín B, Rodríguez-Paz ML, Calero-Escobar JA (2014) El torus en cavidad oral, hallazgos en una muestra poblacional de Santiago de Cali. Revista Gastrohnup 16: 95-100.

23. Singh AK, Ramachandra SS, Arora S, Dicksit DD, Kalyan CG, et al. (2017) Prevalence of oral tori and exostosis in Malaysian population-A cross-sectional study. J Oral Biol Craniofac Res 7: 158160.

24. Auškalnis A, Bernhardt O, Putnienė E, Šidlauskas A, Andriuškevičiūtè I, et al. (2015) Oral bony outgrowths: Prevalence and genetic factor influence. Study of twins. Medicina (Kaunas) 51: 228-232. 